\title{
Changes in vitamin biomarkers during a 2-year intervention trial involving increased fruit and vegetable consumption by free-living volunteers
}

\author{
Helen M. Macdonald ${ }^{1}$, Antonia C. Hardcastle ${ }^{1}$, Garry G. Duthie ${ }^{2}$, Susan J. Duthie ${ }^{2}$, Lorna Aucott ${ }^{1}$, \\ Rena Sandison ${ }^{3}$, Martin J. Shearer ${ }^{4}$ and David M. Reid ${ }^{1}$ \\ ${ }^{1}$ Division of Applied Medicine, University of Aberdeen, Foresterhill, Aberdeen AB25 2ZD, UK \\ ${ }^{2}$ The Rowett Institute of Nutrition and Health, University of Aberdeen, Bucksburn, Aberdeen AB21 9SB, UK \\ ${ }^{3}$ Osteoporosis Scanning Unit, Woolmanhill, Aberdeen AB25 1LD, UK \\ ${ }^{4}$ Centre for Haemostasis and Thrombosis, Guy's and St Thomas' NHS Foundation Trust, London SE1 7EH, UK
}

(Received 7 November 2008 - Revised 1 May 2009 - Accepted 1 May 2009 - First published online 19 June 2009)

Trials in free-living populations involving increased consumption of fruit and vegetables are difficult to monitor. We evaluated biomarkers for assessing fruit and vegetable intake and compliance in a 2-year trial. Postmenopausal women were randomised to $300 \mathrm{~g}$ additional fruit and vegetables per $\mathrm{d}(n$ 66), placebo $(n$ 70) or potassium citrate $(n$ 140). They completed dietary checklists (3-monthly) and food diaries or FFQ (yearly). We measured whole-blood folate, plasma vitamin $\mathrm{C}$ and homocysteine (yearly), serum vitamin $\mathrm{E}$ and carotenoids (at 12 months) and urinary vitamin $\mathrm{K}$ metabolites (yearly). Plasma vitamin $\mathrm{C}$ was associated with fruit and vegetable intake at baseline $(r+0.31 ; P<0.01)$, remaining significant only for the non-fruit and vegetable group at 12 months $(r+0 \cdot 43 ; P<0 \cdot 01)$. For the fruit and vegetable group, vitamin $\mathrm{C}$ increased by $5.9 \mu \mathrm{mol} / 1(P=0.07)$ but was not significantly associated with fruit and vegetable intake; vitamin $\mathrm{E}$, $\beta$-carotene and $\beta$-cryptoxanthin were higher compared with the non-fruit and vegetable group $(P<0.05)$; and whole-blood folate and the urinary $5 \mathrm{C}$-aglycone metabolite of vitamin $\mathrm{K}$ were associated with vegetable intake. For all participants plasma vitamin $\mathrm{C}$ increased with increasing fruit and vegetable intakes, reaching a plateau of $90-95 \mu \mathrm{mol} / 1$ at intakes $>500 \mathrm{~g} / \mathrm{d}$, whereas whole-blood folate, $\beta$-carotene and $\beta$-cryptoxanthin continued to increase. Concentrations of vitamin $\mathrm{C}$, folate and $\beta$-cryptoxanthin were lower and the $7 \mathrm{C}$-aglycone metabolite of vitamin $\mathrm{K}$ higher, in smokers compared with non-smokers. Suitable markers for monitoring fruit and vegetable compliance include $\beta$-carotene and $\beta$-cryptoxanthin. Plasma vitamin $\mathrm{C}$ and whole-blood folate may be suitable for monitoring intakes in populations but for monitoring compliance the former may be restricted to low intakes of fruit and vegetables and the latter to vegetable intake.

Fruit intake: Vegetable intake: Vitamin biomarkers

Fruit and vegetable intake may play a role in preventing many chronic diseases including stroke ${ }^{(1)}, \mathrm{CVD}^{(2)}$ and certain cancers $^{(3)}$. More recently, evidence supporting the protective effect of fruit and vegetables against cancer was reported to be less convincing but public health goals of $>600 \mathrm{~g} / \mathrm{d}$ for non-starchy vegetables and fruits have been justified using an integrated approach to the evidence ${ }^{(4)}$.

It is recognised that fruit and vegetable intakes do not meet current guidelines ${ }^{(5)}$. The UK National Diet and Nutrition Survey found that overall women were eating fewer than three portions per $\mathrm{d}$ and although daily intakes were proportionally higher for older women, $78 \%$ of 50 - to 60-year-old women were still eating less than five portions per $\mathrm{d}^{(6)}$. Interventions to increase fruit and vegetable intake have generally shown modest improvements of about $1-1.5$ portions per $\mathrm{d}^{(7-9)}$, estimated from questionnaires. As food diaries are burdensome, short questionnaires are often used $^{(10)}$ but these are still subjective. Biomarkers such as low urinary $\mathrm{pH}^{(11)}$ and carotenoids ${ }^{(12)}$ have been used to help validate fruit and vegetable intakes obtained from questionnaires. Few studies have used biomarkers to assess compliance of a dietary intervention. Increases in plasma vitamin $\mathrm{E}$ (but not vitamin $\mathrm{C}$ ) were observed 12 months after behavioural and nutritional education counselling to increase fruit and vegetable intake ${ }^{(13)}$ and some plasma carotenoids and plasma vitamin $\mathrm{C}$ increased in a 6-month trial of a brief negotiation method aimed at increasing fruit and vegetable intakes ${ }^{(8)}$, both studies being carried out in a primary-care setting. As far as we are aware there are no data on longerterm studies.

In our randomised controlled trial of free-living postmenopausal women, one of the interventions required extra fruit and vegetable consumption $(300 \mathrm{~g} / \mathrm{d})$, over 2 years. The results of the potassium citrate and fruit and vegetable intervention on bone health have been published elsewhere ${ }^{(14)}$. The aim of the present study was (1) to evaluate concentrations of vitamins

Abbreviations: 5C-aglycone, 2-methyl-3-(3'-3'-carboxymethylpropyl)-1,4-naphthoquinone; 7C-aglycone, 2-methyl-3-(5'-carboxy-3'-methyl-2'-pentenyl)-1,4naphthoquinone; IQR, interquartile range.

* Corresponding author: Dr Helen Macdonald, fax +44 1224 559348, email h.macdonald@abdn.ac.uk 
(E, C, K), carotenoids, folate and homocysteine in blood and urine as biomarkers for assessing overall fruit and vegetable intakes and to assess compliance in the fruit and vegetable intervention group and (2) to compare the relationship between these biomarkers and fruit and vegetable intake in those who were asked to increase their intake of fruit and vegetables with those who were not.

\section{Methods}

\section{Study subjects}

Ethical permission was obtained from Grampian Research Ethics Committee (no. 02/0053) and the study registered with the International Standard Randomised Controlled Trial Number Register (no. ISRCTN86186352). Study participants took part in a randomised placebo-controlled trial in which 276 women were randomised as follows: 140 women to one of two doses of potassium citrate treatment $(18.5 \mathrm{mEq} / \mathrm{d}$ or $55.6 \mathrm{mEq} / \mathrm{d}$ ), seventy women to placebo, and sixty-six women were assigned to the fruit and vegetable intervention $\operatorname{arm}^{(14)}$. Women were excluded if they suffered from severe disease, malabsorption, were taking medications that affected bone metabolism, or were currently taking K-sparing diuretics. In total 226 women completed the 2-year trial (Fig. 1).

All women completed a food diary before the baseline visit. For the fruit and vegetable arm, a nutritionist recommended a daily intake of fruit and vegetables specifically for each individual, based on their current intake estimated from the food diary plus an additional $300 \mathrm{~g}$. The other groups were asked not to change their diet. At the baseline visit, the research nurse explained what total quantity of fruit and vegetables each volunteer had to eat each day; she provided health promotion leaflets on how to increase fruit and vegetables in
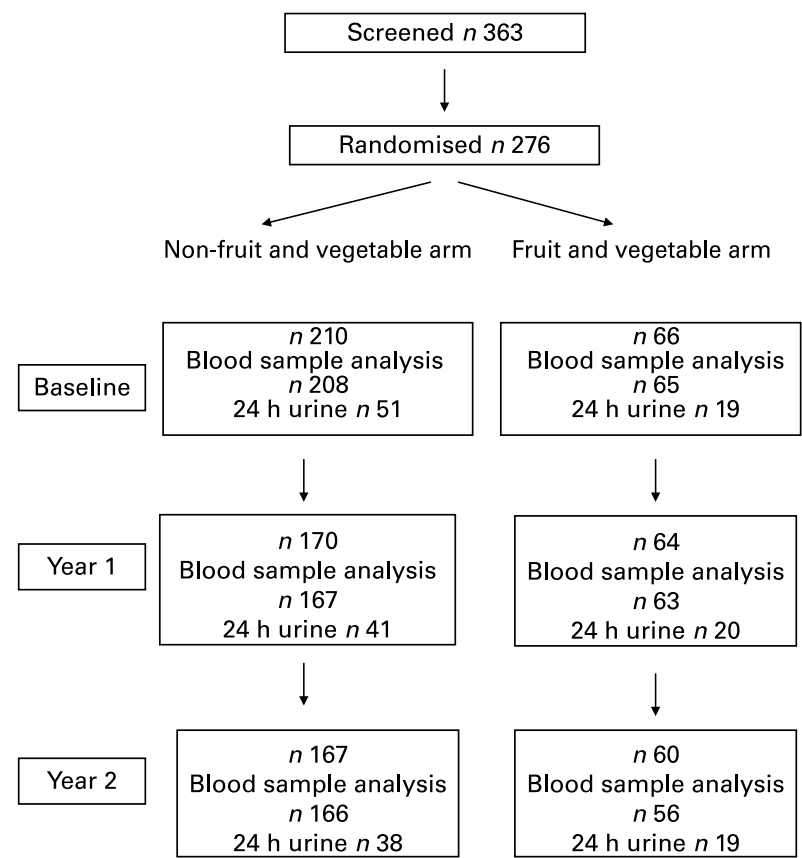

Fig. 1. Numbers of women randomised to the fruit and vegetable and nonfruit and vegetable arms, showing samples collected at yearly time points and study retention. the diet, explained portion sizes, using a range of colour photographs ${ }^{(15)}$ and clarified that fruit juice and pulses could each be counted as a maximum of one portion per $d$. This was repeated at each 3-month visit with discussions on how the volunteers were managing and what was helpful to meet their target intakes. A small financial contribution ( $£ 1$ per $d$ ) was given to help with the expense of purchasing additional fruit and vegetables, and the women were asked to bring in their shopping receipts at each visit to aid compliance.

\section{Dietary intake assessments}

All women in the study underwent regular dietary assessments. A 4d food diary was completed before the baseline visit and at the 1-year visit only. The European Prospective Investigation into Cancer and Nutrition (EPIC) food diary that was used included photographs for portion size estimation $^{(16)}$ and nutrient analysis was carried out using the Windiets dietary analysis program (version 2003; Robert Gordon University, Aberdeen, UK). A FFQ was completed at 21 months $^{(17)}$. Total fruit intake was defined as all fruit including tinned and dried fruit (nuts were excluded) and vegetables did not include potatoes.

A $3 \mathrm{~d}$ dietary checklist was also completed before each 3-month visit. This consisted of a single page with a list of fruits, vegetables and other foods, and spaces for the volunteer to mark every time that food had been eaten during the $3 \mathrm{~d}$. The research nurse collected information on portion size at baseline and 3 months and from 6 months onwards the women were asked if their portion sizes had changed. If information was unavailable then standard portion sizes were used $^{(18)}$.

\section{Anthropometric assessments}

The women were weighed every 6 months on a set of balance scales (Seca, Hamburg, Germany) and height was measured at baseline and 2-year visits using a stadiometer (Holtain Ltd, Crymych, Dyfed, UK). An estimate of physical activity level was obtained using the same questions as used for the Scottish Heart Health Study ${ }^{(19)}$.

\section{Blood biomarker measurements}

Blood samples for whole-blood folate, plasma homocysteine and plasma vitamin $\mathrm{C}$ were collected at baseline, 12 months and 24 months as described previously ${ }^{(14)}$. Analysis of these samples was carried out at the Rowett Research Institute (Aberdeen, UK). Due to time constraints, the baseline and 12-month samples for each subject were analysed together, and the 24-month samples were analysed in a batch at the end of the study. Vitamin E, retinol and the carotenoids were measured in the placebo and fruit and vegetable arms at 12 months only. Vitamin C (plasma), vitamin E ( $\alpha$ - and $\beta$-tocopherol), retinol and several carotenoids $(\alpha$-carotene, $\beta$-carotene, $\beta$-cryptoxanthin, lycopene, lutein/zeaxanthin) (serum) were determined by HPLC under the auspices of the US National Institute of Standards Quality Assurance Program as described in detail by Duthie ${ }^{(20)}$. Total plasma homocysteine was measured by reverse-phase HPLC using the DC30 Hcy Homocysteine Assay Kit in combination with 
a DC30 analyser (Drew Scientific, Barrow-in-Furness, Cumbria, UK). Whole-blood folate was measured by RIA (Simultrac Radioassay Kit; MP Biomedical, London, UK), and expressed per $\mathrm{g} \mathrm{Hb}$ which was measured in the same sample using the Total Haemoglobin Kit (Sigma Diagnostics, Poole, Dorset, UK), with appropriate internal standards. Within-assay variation was $3.3 \%$ for total plasma homocysteine and $4.4 \%$ for whole-blood folate.

\section{Urinary markers for vitamin $K$}

In a subset of women, $24 \mathrm{~h}$ urine was collected at each visit, which was used for vitamin $\mathrm{K}$ assessment at baseline ( $n$ 66) and 12 months ( $n$ 56). Two urinary vitamin K metabolites, 2-methyl-3-(5'-carboxy-3'-methyl-2'-pentenyl)-1, 4-naphthoquinone (7C-aglycone) and 2-methyl-3-(3'-3'-carboxymethylpropyl)-1,4-naphthoquinone (5C-aglycone), were measured in the $24 \mathrm{~h}$ urine samples (previously stored at $\left.-80^{\circ} \mathrm{C}\right)$ by $\operatorname{HPLC}^{(21)}$.

\section{Statistical analysis}

SPSS for Windows (version 15; SPSS Inc., Chicago, IL, USA) was used for analysing the data. Independent $t$ tests were used to detect differences in blood and urinary biomarkers between the combined non-fruit and vegetable group and the fruit and vegetable arm. For the serum tocopherols and carotenoids, the differences tested were between the placebo and fruit and vegetable arm. Repeated-measures ANOVA were used to test changes in biomarkers from baseline. Pearson correlations were used to test for significant associations between biomarkers

Table 1. Subject characteristics according to treatment group

(Mean values and standard deviations or percentages) at baseline and 12 months with intake of fruit and vegetables (estimated from food diaries completed at baseline and 12 months), and for biomarkers at 24 months with intake at 21 months (assessed by FFQ). For all women in the study (n 231 at 12 months), subjects were categorised into four groups according to their fruit and vegetable intakes $(<250 \mathrm{~g} / \mathrm{d}$, $250-500 \mathrm{~g} / \mathrm{d}, 500-750 \mathrm{~g} / \mathrm{d},>750 \mathrm{~g} / \mathrm{d})$ and differences in biomarkers according to category of fruit and vegetable intake were analysed by one-way ANOVA with analysis of covariance to adjust for smoking. $P<0.05$ was considered significant.

\section{Results}

The characteristics of the participants in the fruit and vegetable, and combined non-fruit and vegetable groups are shown in Table 1. The women in each group had similar dietary intakes at baseline but the fruit and vegetable group was heavier $(P=0.05)$ and had increased intakes of dietary PUFA $(P=0 \cdot 02)$. There were no differences in baseline plasma vitamin $\mathrm{C}$ and whole-blood folate but plasma homocysteine was higher in the fruit and vegetable group $(P=0.02)$.

\section{Fruit and vegetable intakes}

For the fruit and vegetable group, estimates of fruit and vegetable intakes by dietary checklists were significantly higher from 3 months onwards compared with the baseline visit whereas there was no change for the non-fruit and vegetable group (Fig. 2). The magnitude of the increase was much greater for fruit compared with vegetables (at 12 months the median increase for fruit was 228 (interquartile

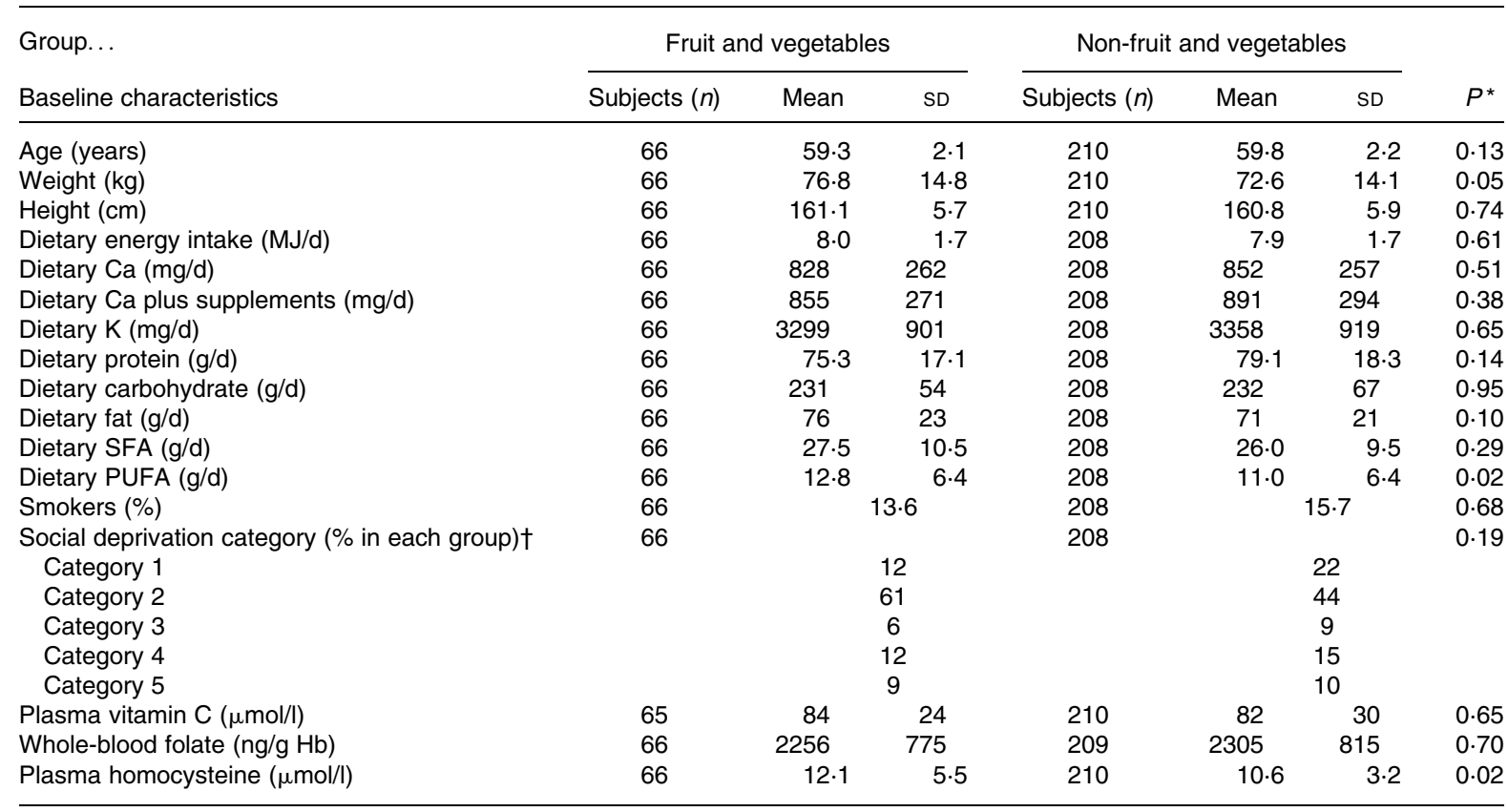

\footnotetext{
* Independent $t$ tests (variable log transformed if required) and $\chi^{2}$ tests were performed between the fruit and vegetable group and the non-fruit and vegetable group.
}

† Category 1 is the least deprived and 5 the most deprived. 


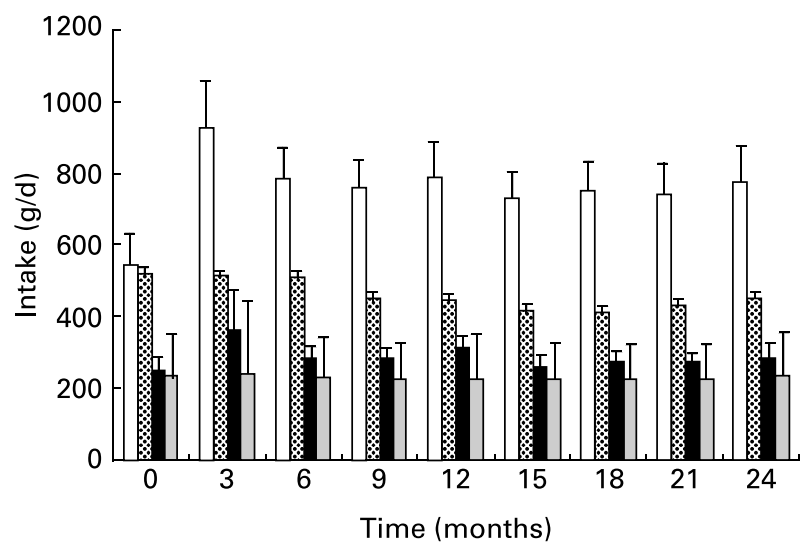

Fig. 2. Fruit and vegetable intakes at 3-month intervals for the fruit and vegetable (FV) group and the non-fruit and vegetable (non-FV) group, as assessed by dietary checklist. ( $\square$ ), Fruit intake, FV group; (图), fruit intake, non-FV group; (ם), vegetable intake, FV group; $(\square)$, vegetable intake, non-FV group. Values are means, with $95 \% \mathrm{Cl}$ represented by vertical bars. For the FV group there was a significant increase in fruit intake following the start of the intervention (paired $t$ test comparisons with baseline, $P=0.001$ for all subsequent visits). There was a small but significant increase in vegetable intake $(P<0.01$ for all visits except for 15 months where $P=0.04)$. At 12 months the median increase for fruit was 228 (interquartile range (IQR) 59389 ) $\mathrm{g} / \mathrm{d}$ and for vegetables 67 (IQR -24 to 154) $\mathrm{g} / \mathrm{d}$. For the non-FV group, compared with baseline intakes there was no significant change in intakes of either fruit or vegetables. At 12 months fruit intake decreased by 25 (IQR -189 to 107$) \mathrm{g} / \mathrm{d}$, and vegetable intake increased by 17 (IQR -50 to 91) $\mathrm{g} / \mathrm{d}$; neither change was significant.

range (IQR) 59-389) g/d and for vegetables 67 (IQR -24 to $154) \mathrm{g} / \mathrm{d}$ ). For the non-fruit and vegetable group, reported fruit intake decreased by 25 (IQR - 189 to 107) g/d, and vegetable intake increased by 17 (IQR -50 to 91 ) g/d. Food diaries completed at 1 year also showed that since the first visit, daily fruit intake had increased by a median of 298 (IQR 97-404) $\mathrm{g}$ and daily vegetable intake had increased by a median of 40 (IQR -16 to 88 ) $g$ for the fruit and vegetable group, whereas for the non-fruit and vegetable group, daily fruit intake had decreased by a median of 8 (IQR -116 to 69) $\mathrm{g} / \mathrm{d}$ and daily vegetable intake had decreased by 10 (IQR -61 to 52$) \mathrm{g} / \mathrm{d}$. The increase in fruit intake was achieved through increased consumption of fruit juice, melon, bananas and apples and this was consistent for the food diary and checklist at 1 year. Seasonal differences were apparent in the 3-month checklist (going from summer to autumn), with increased intake of pears and tangerines, and a decrease in intake of peaches/nectarines and berries, a trend observed in both groups.

\section{Biomarker measurements for fruit and vegetable intervention and placebo}

There were no differences in terms of changes in the perprotocol biomarker measurements (plasma homocysteine, whole-blood folate and plasma vitamin C) between the fruit and vegetable intervention and the non-fruit and vegetable group. Plasma vitamin $\mathrm{C}$ increased incrementally from baseline to the 24-month visit for the non-fruit and vegetable group ( $P=0.06$ for 24-month comparison with baseline) and for the fruit and vegetable group plasma vitamin $\mathrm{C}$ had increased at 12 months $(P=0 \cdot 07)$ with no further increase.
Dietary intakes of folate estimated from food diaries showed an increase at 1 year of $33 \mu \mathrm{g}$ per $\mathrm{d}$ for the fruit and vegetable group and a decrease of $16 \mu \mathrm{g}$ per $\mathrm{d}$ in the placebo group. For whole-blood folate, expressed relative to $\mathrm{Hb}$, the incremental increase seen in both groups from baseline to 24 months was not significantly different $(P=0.004$ for the non-fruit and vegetable group; $P=0.085$ for the fruit and vegetable group; repeated-measures ANOVA). Similar trends were seen if the folate was expressed as $\mathrm{ng} / \mathrm{ml}$ lysate (data not shown). For the fruit and vegetable group, plasma homocysteine had decreased from 11.8 (SD 4.5) to 11.4 (SD 4.7) $\mu \mathrm{mol} / \mathrm{l}$ at 12 months and 10.8 (SD 3.9) $\mu \mathrm{mol} / 1$ at 24 months ( $P=0.014 ; n$ 60; repeated-measures ANOVA). Plasma homocysteine for the non-fruit and vegetable group was $10 \cdot 5$ (SD 3.3) $\mu \mathrm{mol} / \mathrm{l}$ at baseline, $10.4(\mathrm{sD} 3 \cdot 1) \mu \mathrm{mol} / \mathrm{l}$ at 12 months and 10.0 (SD 2.9) $\mu \mathrm{mol} / \mathrm{l}$ at 24 months $(P=0.001 ; n 163$; repeatedmeasures ANOVA). Again, there was little difference in the magnitude of the change between the two groups.

Plasma vitamin $\mathrm{C}$ was positively correlated with intakes of fruit, fruit and vegetables, and dietary vitamin $\mathrm{C}$ (estimated from diaries or FFQ) throughout the study for the non-fruit and vegetable group but only at baseline for the fruit and vegetable intervention group (Table 2). For whole-blood folate, there was a significant association with fruit and vegetable intake for both groups at 12 months (Table 2). There were no significant associations between plasma homocysteine and fruit and vegetable intakes. The findings did not change after adjusting for smoking status (current smoker/nonsmoker). There was a negative correlation between wholeblood folate and plasma homocysteine, which was significant $(P<0.001$ for all visits) for the complete study population (Pearson's correlations for the log-transformed variables were $r-0.40$ at baseline, $r-0.36$ at 1 year and $r-0.37$ at 2 years). The results were similar when tested for the fruit and vegetable group only (complete data not shown).

\section{Additional post-study biomarker measurements and comparison with other biomarkers}

At 12 months, concentrations of $\beta$-carotene, $\beta$-cryptoxanthin, $\alpha$-tocopherol and $\gamma$-tocopherol, expressed per mmol cholesterol, were significantly greater in the fruit and vegetable intervention group compared with the placebo group (Table 3). In comparison, differences in plasma vitamin $\mathrm{C}$, whole-blood folate, plasma homocysteine and urinary $\mathrm{K}$ were not statistically significant between the two groups at 12 months.

Mean urinary vitamin $\mathrm{K}$ metabolites varied markedly between the treatment groups at baseline, with the placebo group having significantly lower mean urinary vitamin $\mathrm{K}$ compared with the fruit and vegetable group. At 12 months the difference between the treatment groups was not significant. At baseline there was no association between urinary vitamin $\mathrm{K}$ metabolites and fruit and vegetable intake (Table 4). At 12 months there was a positive correlation between the 5C-aglycone urinary marker and vegetable intake $(r 0.27 ; P=0.047)$ but not with fruit intake, and dietary intake of vitamin $\mathrm{K}_{1}$ estimated from food diaries correlated with the 5C-aglycone urinary marker ( $r \quad 0 \cdot 30$; $P=0.026)$. The association between vegetable intake, dietary vitamin $\mathrm{K}_{1}$ and the $7 \mathrm{C}$-aglycone marker was not significant (complete data not shown). 


\section{Associations between biomarkers and category of fruit and} vegetable intake

When all the women taking part in the study at 12 months ( $n$ 231), regardless of treatment group, were divided into categories according to fruit and vegetable intake $(<250$, $250-500,500-750 \mathrm{~g} / \mathrm{d}$ ) it was found that weight and energy intake increased, and number of smokers decreased, with increasing intakes of fruit and vegetables (Table 5). Plasma vitamin $\mathrm{C}$ increased with increasing category of fruit and vegetables up to $500 \mathrm{~g} / \mathrm{d}$ but with no further increase for intakes above $500 \mathrm{~g} / \mathrm{d}$. Whole-blood folate mean values were similar for categories of $<250 \mathrm{~g} / \mathrm{d}$ and up to $500 \mathrm{~g} / \mathrm{d}$ fruit and vegetable intake, then increased from $500 \mathrm{~g} / \mathrm{d}$ to $500-750 \mathrm{~g} / \mathrm{d}$ and $>750 \mathrm{~g} / \mathrm{d}$ (Table 6). There was no relationship between serum tocopherol and category of fruit and vegetable intake, although when expressed relative to serum cholesterol there was a significant increase in $\alpha$-tocopherol. The carotenoids $\beta$-carotene, $\beta$-cryptoxanthin and $\alpha$-carotene also increased progressively with category of fruit and vegetable intake. A similar trend for the urinary vitamin $\mathrm{K}$ metabolites (measured in fifty-five women) was not statistically significant.

\section{Smoking}

Non-smokers had significantly higher circulating plasma vitamin $\mathrm{C}$, whole-blood folate and serum $\beta$-cryptoxanthin compared with smokers. Urinary vitamin $\mathrm{K}$ metabolites were lower in the non-smokers and there was no difference in serum concentrations of $\alpha$ - and $\gamma$-tocopherol between smokers and non-smokers (Table 6). Although the numbers in the $24 \mathrm{~h}$ urine subset were small, the result was statistically significant for the 7C-aglycone vitamin $\mathrm{K}$ metabolite. Fruit and vegetable intakes were significantly lower for the smokers but the significant differences in the biomarker results remained significant after adjustment for total fruit and vegetable intake.

\section{Discussion}

\section{Fruit and vegetable intakes}

Food diaries and checklists suggested good compliance with the dietary intervention but the blood measurements did not corroborate this. We cannot be certain that the discrepancies between biomarkers and reported fruit and vegetable intakes are not due to non-compliance. Interestingly, the placebo group, who did not report increased intake of fruit and vegetables, showed small increases in plasma vitamin $\mathrm{C}$ and whole-blood folate during the study. The women were regularly asked about the portion sizes of different fruits and vegetables they were eating and this, together with public health campaigns with government advice and supermarket promotions to eat '5-a-day', may have made them more aware of fruit and vegetables in general, leading them to inadvertently increase the amount of fruits and vegetables they were eating.

\section{Plasma vitamin $C$, folate and homocysteine}

We observed a significant association between fruit and vegetable intake and plasma vitamin $\mathrm{C}$ at all visits for the 
Table 3. Serum vitamin $E$ and carotenoids and other markers assessed at the 12-month visit for the placebo and fruit and vegetable groups only

(Mean values and standard deviations)

\begin{tabular}{|c|c|c|c|c|c|}
\hline \multirow{2}{*}{ Group... } & \multicolumn{2}{|c|}{ Placebo } & \multicolumn{2}{|c|}{ Fruit and vegetables } & \multirow[b]{2}{*}{$P^{\star}$} \\
\hline & Mean & SD & Mean & SD & \\
\hline Serum measurements $(n)$ & \multicolumn{2}{|c|}{55} & \multicolumn{2}{|c|}{63} & \\
\hline Cholesterol (mmol/l) & $6 \cdot 0$ & 1.0 & 5.8 & 1.2 & 0.37 \\
\hline$\alpha$-Tocopherol $(\mu \mathrm{mol} / \mathrm{l})$ & 25.4 & 5.6 & $29 \cdot 1$ & $6 \cdot 1$ & 0.001 \\
\hline$\alpha$-Tocopherol $(\mu \mathrm{mol} / \mathrm{mmol}$ cholesterol) & 4.2 & 0.7 & $5 \cdot 1$ & 1.0 & $<0.001$ \\
\hline$\gamma$-Tocopherol $(\mu \mathrm{mol} / \mathrm{l})$ & $1 \cdot 24$ & 0.55 & 1.43 & 0.57 & 0.08 \\
\hline$\gamma$-Tocopherol $(\mu \mathrm{mol} / \mathrm{mmol}$ cholesterol $)$ & 0.21 & 0.09 & 0.25 & 0.11 & 0.02 \\
\hline$\alpha$-Carotene $(\mu \mathrm{mol} / \mathrm{l})$ & 0.121 & 0.075 & 0.143 & 0.079 & 0.14 \\
\hline$\beta$-Carotene $(\mu \mathrm{mol} / \mathrm{l})$ & 0.40 & 0.23 & 0.50 & 0.27 & 0.04 \\
\hline$\beta$-Cryptoxanthin $(\mu \mathrm{mol} / \mathrm{l})$ & 0.155 & 0.140 & 0.212 & 0.159 & 0.02 \\
\hline Lutein/zeaxanthin $(\mu \mathrm{mol} / /)$ & 0.27 & 0.11 & 0.31 & 0.17 & 0.54 \\
\hline Lycopene $(\mu \mathrm{mol} / \mathrm{l})$ & 0.48 & 0.23 & 0.51 & 0.29 & 0.56 \\
\hline Retinol $(\mu \mathrm{mol} / \mathrm{l})$ & 1.71 & 0.34 & 1.82 & 0.38 & 0.10 \\
\hline Other biomarkers $(n)$ & \multicolumn{2}{|c|}{57} & \multicolumn{2}{|c|}{64} & \\
\hline Plasma vitamin $C(\mu \mathrm{mol} / \mathrm{l})$ & 81 & 31 & 89 & 25 & 0.13 \\
\hline Whole-blood folate (ng/g Hb) & 2343 & 730 & 2367 & 618 & 0.71 \\
\hline Plasma homocysteine $(\mu \mathrm{mol} / \mathrm{l})$ & $10 \cdot 1$ & 3.0 & $11 \cdot 3$ & 4.6 & 0.09 \\
\hline $24 \mathrm{~h}$ urine $(n)$ & \multirow{2}{*}{\multicolumn{2}{|c|}{$54 \cdot 7 \quad 14$}} & \multicolumn{2}{|c|}{20} & \\
\hline K excretion (mmol) & & & 65.5 & $22 \cdot 1$ & 0.19 \\
\hline
\end{tabular}

combined non-fruit and vegetable groups but not during the intervention for the fruit and vegetable group. The mean plasma vitamin $\mathrm{C}$ of $82-84 \mu \mathrm{mol} / \mathrm{l}$ may have been optimal at the start of the study ${ }^{(22)}$. This is much higher than the mean baseline value of $34 \mu \mathrm{mol} / \mathrm{l}$ reported in a 6 -month study involving 690 subjects aged 25-64 years, half of whom were encouraged to increase their fruit and vegetable intake to five portions per $\mathrm{d}^{(8)}$. At 6 months their daily fruit and vegetable consumption (estimated by questionnaire) had increased by 1.4 portions and plasma vitamin $\mathrm{C}$ by $1 \mu \mathrm{mol} / \mathrm{l}$. In the present study, a reported increase of three portions per $\mathrm{d}$ resulted in a non-significant increase in plasma vitamin $\mathrm{C}$ of $5.9 \mu \mathrm{mol} / \mathrm{l}$ at 12 months. A study of 105 men and 166 women (mean age 40 and 48 years, respectively) showed that plasma vitamin $\mathrm{C}$ was $68.2 \mu \mathrm{mol} / \mathrm{l}$ for intakes of $<2.5$ portions, $81.3 \mu \mathrm{mol} / \mathrm{l}$ for intakes of $3-4.5$ portions, decreasing slightly to $78 \cdot 2 \mu \mathrm{mol} / 1$ for intakes $>$ five portions per $\mathrm{d}^{(23)}$. Assuming a portion size of $100 \mathrm{~g}$, our data are comparable with a mean plasma vitamin $\mathrm{C}$ of $63 \mu \mathrm{mol} / \mathrm{l}$ for $<2.5$ and $80 \mu \mathrm{mol} / \mathrm{l}$ for up to five portions per d. Above these intakes we observed a similar plateau for plasma vitamin $\mathrm{C}$, although at a higher concentration $(95 \mu \mathrm{mol} / 1$ for $5-7.5$ portions, and $91 \mu \mathrm{mol} / 1$ for $>7.5$ portions). This plateau effect suggests that plasma vitamin $\mathrm{C}$ may be useful for monitoring when intakes of fruit and vegetables are low to moderate but it is not an ideal marker at high intakes. For the European Prospective Investigation into Cancer and Nutrition (EPIC) study there was no plateau effect: the mean for the top quintile

Table 4. Urinary vitamin $\mathrm{K}$ metabolites according to treatment group

(Mean values and standard deviations)

\begin{tabular}{|c|c|c|c|c|c|}
\hline \multirow[t]{2}{*}{ Group... } & \multicolumn{2}{|c|}{ Placebo } & \multicolumn{2}{|c|}{$\begin{array}{c}\text { Fruit and } \\
\text { vegetables }\end{array}$} & \multirow[b]{2}{*}{$P^{*}$} \\
\hline & Mean & SD & Mean & SD & \\
\hline Provided $24 \mathrm{~h}$ urine samples at baseline $(n)$ & \multicolumn{2}{|c|}{15} & \multicolumn{2}{|c|}{19} & \\
\hline $5 \mathrm{C}$-aglycone $(\mu \mathrm{g} / \mathrm{d})$ & 2.5 & 1.0 & $3 \cdot 8$ & $1 \cdot 8$ & 0.02 \\
\hline 7C-aglycone $(\mu \mathrm{g} / \mathrm{d})$ & 0.52 & 0.25 & 0.97 & 0.50 & 0.01 \\
\hline Provided $24 \mathrm{~h}$ urine samples at 12 months $(n)$ & \multicolumn{2}{|c|}{12} & \multicolumn{2}{|c|}{19} & \\
\hline 5C-aglycone $(\mu \mathrm{g} / \mathrm{d})$ & $3 \cdot 3$ & 2.5 & 3.6 & 1.9 & 0.53 \\
\hline 7C-aglycone $(\mu \mathrm{g} / \mathrm{d})$ & 0.73 & 0.27 & 0.88 & 0.53 & 0.70 \\
\hline Change at 12 months from baseline $(n)$ & \multicolumn{2}{|c|}{12} & \multicolumn{2}{|c|}{19} & \\
\hline Change in $5 \mathrm{C}$-aglycone $(\mu \mathrm{g} / \mathrm{d})$ & +0.7 & $2 \cdot 6$ & -0.3 & $1 \cdot 8$ & 0.13 \\
\hline Change in $7 \mathrm{C}$-aglycone $(\mu \mathrm{g} / \mathrm{d})$ & $+0 \cdot 16$ & 0.43 & -0.09 & 0.54 & 0.08 \\
\hline
\end{tabular}


Table 5. Biomarker change with increasing category of fruit and vegetable intake from the food diary at 12 months (Mean values and standard deviations or percentages)

\begin{tabular}{|c|c|c|c|c|c|c|c|c|c|}
\hline & \multicolumn{8}{|c|}{ Fruit and vegetable intake $(\mathrm{g} / \mathrm{d})$} & \multirow[b]{3}{*}{$P^{*} \dagger$} \\
\hline & \multicolumn{2}{|c|}{$<250$} & \multicolumn{2}{|c|}{$250-500$} & \multicolumn{2}{|c|}{$500-750$} & \multicolumn{2}{|c|}{$>750 \mathrm{~g} / \mathrm{d}$} & \\
\hline & Mean & SD & Mean & SD & Mean & SD & Mean & SD & \\
\hline Subjects $(n)$ & \multicolumn{2}{|c|}{40} & \multicolumn{2}{|c|}{76} & \multicolumn{2}{|c|}{66} & \multicolumn{2}{|c|}{49} & \\
\hline Baseline characteristics & & & & & & & & & \\
\hline Age (years) & $59 \cdot 1$ & 1.9 & $60 \cdot 1$ & $2 \cdot 3$ & $59 \cdot 7$ & $2 \cdot 2$ & $60 \cdot 0$ & $2 \cdot 3$ & 0.112 \\
\hline Weight (kg) & $70 \cdot 6$ & $13 \cdot 3$ & $70 \cdot 2$ & 13.5 & $76 \cdot 8$ & $14 \cdot 7$ & $72 \cdot 7$ & $14 \cdot 0$ & 0.030 \\
\hline Dietary energy intake $(\mathrm{MJ} / \mathrm{d})$ & $7 \cdot 3$ & 1.8 & 7.9 & 1.5 & $8 \cdot 2$ & 1.8 & 8.5 & 1.6 & 0.003 \\
\hline $\begin{array}{l}\text { Smokers }(\%) \\
\text { Social deprivation category (\% in each } \\
\text { group) } \ddagger\end{array}$ & \multicolumn{2}{|c|}{$30 \cdot 0$} & \multicolumn{2}{|c|}{$21 \cdot 1$} & \multicolumn{2}{|c|}{$6 \cdot 1$} & \multicolumn{2}{|c|}{$4 \cdot 1$} & $\begin{array}{r}<0.001 \\
0.298\end{array}$ \\
\hline Category 1 & \multicolumn{2}{|c|}{15} & \multicolumn{2}{|c|}{25} & \multicolumn{2}{|c|}{17} & \multicolumn{2}{|c|}{21} & \\
\hline Category 2 & \multicolumn{2}{|c|}{42} & \multicolumn{2}{|c|}{43} & \multicolumn{2}{|c|}{56} & \multicolumn{2}{|c|}{57} & \\
\hline Category 3 & \multicolumn{2}{|c|}{10} & \multicolumn{2}{|c|}{5} & \multicolumn{2}{|c|}{8} & \multicolumn{2}{|c|}{12} & \\
\hline Category 4 & & & & & & & & & \\
\hline Category 5 & & & & & & & & & \\
\hline 12-month measurements & & & & & & & & & \\
\hline Dietary energy intake (MJ/d) & $7 \cdot 7$ & 1.7 & 7.9 & 1.8 & $8 \cdot 1$ & 1.8 & 8.8 & 1.8 & 0.015 \\
\hline Fruit intake $(\mathrm{g} / \mathrm{d})$ & 89 & 55 & 226 & 84 & 427 & 102 & 699 & 222 & $<0.001$ \\
\hline Vegetable intake $(\mathrm{g} / \mathrm{d})$ & 87 & 48 & 143 & 69 & 191 & 88 & 260 & 108 & $<0.001$ \\
\hline Total fruit and vegetable intake $(\mathrm{g} / \mathrm{d})$ & 176 & 62 & 369 & 71 & 619 & 69 & 959 & 249 & $<0.001$ \\
\hline Plasma vitamin $C(\mu \mathrm{mol} / \mathrm{l})$ & 63 & 27 & 80 & 24 & 95 & 27 & 91 & 25 & $<0.001$ \\
\hline Whole-blood folate (ng/g Hb) & 2214 & 887 & 2215 & 640 & 2459 & 698 & 2607 & 684 & 0.002 \\
\hline Plasma homocysteine $(\mu \mathrm{mol} / \mathrm{l})$ & $10 \cdot 9$ & $2 \cdot 8$ & $10 \cdot 6$ & 3.6 & $10 \cdot 7$ & 4.4 & 10.4 & $2 \cdot 9$ & 0.792 \\
\hline Serum carotenoids and tocopherols $(n)$ & & & & & & & & & \\
\hline Cholesterol (mmol/l) & $6 \cdot 0$ & $1 \cdot 1$ & $6 \cdot 2$ & $1 \cdot 0$ & 5.9 & 1.0 & 5.6 & $1 \cdot 2$ & 0.135 \\
\hline$\alpha$-Tocopherol $(\mu \mathrm{mol} / \mathrm{l})$ & $25 \cdot 6$ & $5 \cdot 2$ & $26 \cdot 8$ & $6 \cdot 2$ & $27 \cdot 0$ & $5 \cdot 9$ & $29 \cdot 0$ & 6.7 & 0.319 \\
\hline$\alpha$-Tocopherol $(\mu \mathrm{mol} / \mathrm{mmol}$ cholesterol) & $4 \cdot 3$ & 0.7 & $4 \cdot 3$ & 0.8 & 4.6 & 1.0 & $5 \cdot 2$ & 1.0 & $<0.001$ \\
\hline$\gamma$-Tocopherol $(\mu \mathrm{mol} / \mathrm{l})$ & 1.64 & 0.60 & 1.27 & 0.48 & 1.31 & 0.53 & 1.38 & 0.66 & 0.322 \\
\hline$\gamma$-Tocopherol $(\mu \mathrm{mol} / \mathrm{mmol}$ cholesterol $)$ & 0.28 & 0.11 & 0.21 & 0.08 & 0.22 & 0.09 & 0.25 & 0.13 & 0.115 \\
\hline$\alpha$-Carotene $(\mu \mathrm{mol} / \mathrm{l})$ & 0.095 & 0.069 & 0.127 & 0.065 & 0.127 & 0.065 & 0.159 & 0.090 & 0.049 \\
\hline$\beta$-Carotene $(\mu \mathrm{mol} / \mathrm{l})$ & 0.25 & 0.14 & 0.42 & 0.19 & 0.45 & 0.25 & 0.53 & 0.30 & 0.010 \\
\hline$\beta$-Cryptoxanthin $(\mu \mathrm{mol} / \mathrm{l})$ & 0.071 & 0.044 & 0.164 & 0.158 & 0.182 & 0.122 & 0.245 & 0.178 & $<0.001$ \\
\hline Lutein/zeaxanthin $(\mu \mathrm{mol} / /)$ & 0.25 & 0.10 & 0.28 & 0.10 & 0.28 & 0.14 & 0.33 & 0.18 & 0.509 \\
\hline Lycopene $(\mu \mathrm{mol} / \mathrm{l})$ & 0.41 & 0.26 & 0.59 & 0.29 & 0.43 & 0.19 & 0.50 & 0.29 & 0.058 \\
\hline Retinol $(\mu \mathrm{mol} / \mathrm{l})$ & $1 \cdot 71$ & 0.30 & 1.66 & 0.33 & 1.87 & 0.37 & 1.78 & 0.40 & 0.121 \\
\hline Urinary vitamin $\mathrm{K}$ metabolites $(n)$ & & & & & & & & & \\
\hline 5C-aglycone $(\mu \mathrm{g} / \mathrm{d})$ & $2 \cdot 4$ & $1 \cdot 0$ & $3 \cdot 3$ & $2 \cdot 2$ & $3 \cdot 2$ & 1.8 & 3.7 & $2 \cdot 0$ & 0.360 \\
\hline 7C-aglycone $(\mu \mathrm{g} / \mathrm{d})$ & 0.74 & 0.44 & 0.73 & 0.35 & 0.78 & 0.31 & 0.90 & 0.59 & 0.859 \\
\hline
\end{tabular}

5C-aglycone, 2-methyl-3-(3'-3'-carboxymethylpropyl)-1,4-naphthoquinone; 7C-aglycone, 2-methyl-3-(5'-carboxy-3'-methyl-2'-pentenyl)-1,4-naphthoquinone; ANCOVA, analysis of covariance.

* One-way ANOVA. Variables were log transformed if not normally distributed ( $\alpha$-carotene, $\beta$-cryptoxanthin, lutein/zeaxanthin, whole-blood folate, plasma homocysteine and urinary vitamin $\mathrm{K}$ metabolites).

†Using ANCOVA, smoking was significantly associated with $\beta$-cryptoxanthin $(P=0.003)$, plasma vitamin $\mathrm{C}(P=0.017)$ and whole-blood folate $(P=0.043)$ but adjustment for smoking by ANCOVA only slightly attenuated the relationship with category of fruit and vegetable intake. Weight was no longer associated with category of fruit and vegetable intake when adjusted for smoking $(P=0.091$ for category of fruit and vegetable intake; $P=0.016$ for smoking). Smoking was not associated with dietary energy intake and adjustment for smoking did not change the relationship with category of fruit and vegetable intake $(P=0.038)$.

$\ddagger$ Category 1 is the least deprived and 5 the most deprived.

(quintile 5) of plasma vitamin $\mathrm{C}$ was $80 \mu \mathrm{mol} / \mathrm{l}$ and the mean reported intake of fruit and vegetables was $486 \mathrm{~g} / \mathrm{d}$ by food diary and $824 \mathrm{~g}$ by $\mathrm{FFQ}^{(24)}$.

Blood measures of folate and homocysteine are not specific for fruit and vegetable intake. Not all fruits and vegetables contain large amounts of folate and other foods contain folate, including fortified foods. Plasma homocysteine can be reduced by other $\mathrm{B}$ vitamins (vitamin $\mathrm{B}_{6}, \mathrm{~B}_{12}$ and riboflavin) in addition to dietary folate obtained from fruit and vegetable consumption ${ }^{(25)}$. Plasma homocysteine concentrations decreased similarly for all treatment groups and the effect was not limited to the fruit and vegetable group. This may be due to increased dietary folic acid in the food chain, due to an increasing number of fortified foods (for example, breakfast cereals). In spite of this confounding there was a consistent association between whole-blood folate and fruit and vegetable intake, in particular vegetable intake. A 4-week intervention of seventy-one women in the Netherlands, half of whom were instructed to eat $200 \mathrm{~g}$ vegetables and two portions of fruit and whose reported increase was $133 \mathrm{~g}$ for fruit and $64 \mathrm{~g}$ for vegetables, with an increase in daily folate intake of $33 \mu \mathrm{g}$, showed no effect on homocysteine or plasma folate ${ }^{(26)}$. The authors concluded that the duration of the intervention was probably too short to have an effect. In a more controlled 4-week intervention involving sixty-six subjects of whom twenty-two were given folate-rich vegetables and citrus fruit (estimated to provide an additional $350 \mu \mathrm{g}$ folate per $\mathrm{d}$ ), erythrocyte folate was 
Table 6. Difference in fruit and vegetable intake, plasma vitamin C, whole-blood folate, serum carotenoids and urinary vitamin $\mathrm{K}$ metabolites between smokers and non-smokers

(Mean values and standard deviations)

\begin{tabular}{|c|c|c|c|c|c|}
\hline & \multicolumn{2}{|c|}{ Non-smoker } & \multicolumn{2}{|c|}{ Smoker } & \multirow[b]{2}{*}{$P^{\star}$} \\
\hline & Mean & SD & Mean & SD & \\
\hline Baseline fruit and vegetable intake $(n)$ & \multicolumn{2}{|c|}{246} & \multicolumn{2}{|c|}{46} & \\
\hline Total fruit intake $(\mathrm{g})$ & 304 & 179 & 226 & 167 & 0.007 \\
\hline Total vegetable intake $(\mathrm{g})$ & 173 & 93 & 130 & 61 & $<0.001$ \\
\hline Total fruit and vegetable intake (g) & 477 & 222 & 356 & 192 & 0.001 \\
\hline Baseline biomarkers $(n)$ & \multicolumn{2}{|c|}{236} & \multicolumn{2}{|c|}{43} & \\
\hline Plasma vitamin $\mathrm{C}(\mu \mathrm{mol} / \mathrm{l})$ & 85 & 27 & 68 & 29 & $<0.001$ \\
\hline Whole-blood folate (ng/g Hb) & 2342 & 803 & 1992 & 739 & $<0.001$ \\
\hline Plasma homocysteine $(\mu \mathrm{mol} / \mathrm{l})$ & $10 \cdot 8$ & $3 \cdot 6$ & $12 \cdot 1$ & $5 \cdot 5$ & 0.062 \\
\hline Baseline vitamin K metabolites ( $n$ ) & \multicolumn{2}{|c|}{59} & \multicolumn{2}{|l|}{ 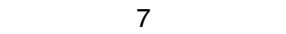 } & \\
\hline 5C-aglycone $(\mu \mathrm{g} / \mathrm{d})$ & $3 \cdot 1$ & 1.4 & $4 \cdot 1$ & 2.5 & 0.55 \\
\hline 7C-aglycone $(\mu \mathrm{g} / \mathrm{d})$ & 0.73 & 0.42 & 1.42 & 0.91 & 0.01 \\
\hline 12-month serum carotenoids and vitamin $\mathrm{E}(n)$ & \multicolumn{2}{|c|}{101} & \multicolumn{2}{|c|}{18} & \\
\hline Cholesterol (mmol/l) & $5 \cdot 9$ & $1 \cdot 1$ & $6 \cdot 2$ & $1 \cdot 2$ & 0.28 \\
\hline$\alpha$-Tocopherol $(\mu \mathrm{mol} / \mathrm{l})$ & $27 \cdot 1$ & $6 \cdot 0$ & $28 \cdot 7$ & $6 \cdot 6$ & 0.33 \\
\hline$\alpha$-Tocopherol ( $\mu \mathrm{mol} / \mathrm{mmol}$ cholesterol) & $4 \cdot 7$ & 0.9 & $4 \cdot 8$ & $1 \cdot 3$ & $0 \cdot 76$ \\
\hline$\gamma$-Tocopherols $(\mu \mathrm{mol} / \mathrm{l})$ & $1 \cdot 33$ & 0.56 & 1.47 & 0.59 & 0.33 \\
\hline$\gamma$-Tocopherol ( $\mu \mathrm{mol} / \mathrm{mmol}$ cholesterol) & 0.23 & $0 \cdot 10$ & $0 \cdot 25$ & 0.12 & 0.52 \\
\hline$\alpha$-Carotene $(\mu \mathrm{mol} / \mathrm{l})$ & $0 \cdot 137$ & 0.079 & $0 \cdot 105$ & 0.064 & $0 \cdot 15$ \\
\hline$\beta$-Carotene $(\mu \mathrm{mol} / \mathrm{l})$ & 0.47 & 0.26 & 0.35 & 0.17 & 0.08 \\
\hline$\beta$-Cryptoxanthin $(\mu \mathrm{mol} / \mathrm{l})$ & 0.201 & $0 \cdot 158$ & 0.087 & 0.053 & 0.001 \\
\hline Lutein/zeaxanthin $(\mu \mathrm{mol} / \mathrm{l})$ & 0.30 & $0 \cdot 15$ & 0.24 & $0 \cdot 10$ & 0.17 \\
\hline Lycopene $(\mu \mathrm{mol} / \mathrm{l})$ & 0.50 & 0.25 & 0.48 & 0.34 & 0.84 \\
\hline Retinol $(\mu \mathrm{mol} / \mathrm{l})$ & $1 \cdot 76$ & 0.32 & 1.78 & 0.58 & 0.90 \\
\hline \multicolumn{6}{|c|}{$\begin{array}{l}\text { 5C-aglycone, 2-methyl-3-(3'-3'-carboxymethylpropyl)-1,4-naphthoquinone; 7C-aglycone, 2-methyl-3-(5'-carboxy-3'-methyl-2'-pente- } \\
\text { nyl)-1,4-naphthoquinone; ANCOVA, analysis of covariance. }\end{array}$} \\
\hline \multicolumn{6}{|c|}{$\begin{array}{l}\text { Independent } t \text { tests between non-smokers and smokers. Variables were log transformed if not normally distributed (whole-blood } \\
\text { folate, plasma homocysteine, urinary vitamin } \mathrm{K} \text { metabolites, } \alpha \text {-carotene, } \beta \text {-cryptoxanthin and lutein/zeaxanthin). By ANCOVA } \\
\text { differences were still significant after adjusting for fruit and vegetable intake (plasma vitamin } C P=0.006 \text {, whole-blood folate } \\
P=0.004,7 \mathrm{C} \text {-aglycone vitamin } \mathrm{K} \text { metabolite } P=0.008 \text { and } \beta \text {-cryptoxanthin } P=0.001 \text {, if adjust for baseline fruit and vegetable } \\
\text { intake; } P=0.005 \text { if adjust for } 12 \text {-month fruit and vegetable intake). }\end{array}$} \\
\hline
\end{tabular}

found to increase by $59 \mathrm{nmol} / \mathrm{l}$ and homocysteine decrease by $1.4 \mu \mathrm{mol} / \mathrm{l}^{(27)}$. Since the small increase we observed in wholeblood folate in the present study was not restricted to the fruit and vegetable group, and mean homocysteine decreased overall, it is likely that fortified foods such as breakfast cereals (which are not often updated in the database) may be influencing dietary folate.

\section{Serum tocopherols and carotenoids}

We observed a significant difference in some carotenoids between the placebo and fruit and vegetable groups at 12 months, and a linear association across categories of fruit and vegetable intakes to $>750 \mathrm{~g} / \mathrm{d}$, suggesting that carotenoids, in particular $\beta$-cryptoxanthin, could be useful as biomarkers across a wide range of intakes. Compared with the elderly Framingham women (aged 67-93 years), the women in the fruit and vegetable intervention group of the present study at 12 months had slightly higher circulating concentrations of $\alpha$-carotene $(0 \cdot 143$ compared with $0.117 \mu \mathrm{mol} / \mathrm{l})$ and the circulating concentrations of $\beta$-carotene, $\beta$-cryptoxanthin, lycopene and lutein/zeaxanthin were similar or marginally lower. In the Framingham women, $9 \%$ were taking $\beta$-carotene supplements and they were eating five servings of fruit and vegetables per $d^{(28)}$. We had no $\beta$-carotene supplement use in our population but portions of fruit and vegetables were similar or higher.
The discrepancy with $\alpha$-tocopherol being higher in the fruit and vegetable group but not being significantly associated with overall fruit and vegetable intake may be due to the fruit and vegetable group having marginally higher intakes of fat (i.e. polyunsaturated fats or oils containing vitamin E).

\section{Urinary markers}

Although we did not observe an association between urinary vitamin $\mathrm{K}$ metabolites and vegetable intake, this may be because the number of subjects that provided $24 \mathrm{~h}$ urine was small and the reported increase in vegetables in the present study was also small. These markers may prove useful for assessing compliance in larger studies involving green vegetables. Similarly, small sample size may partly explain why $\mathrm{K}$ was not significantly higher in the fruit and vegetable group compared with the placebo group. Dietary $\mathrm{K}$ is found in other foods, including milk, making it an inappropriate marker for estimating fruit and vegetable intake in population studies.

\section{Smoking, weight and energy intake}

Energy intake increased with increasing category of fruit and vegetable intake whereas numbers of smokers decreased. Body weight peaked in the $500-750 \mathrm{~g} / \mathrm{d}$ fruit and vegetable category. The decreasing number of smokers, who were 
lighter in weight, could provide an explanation for increasing body weight. When adjustment was made for smoking it did not alter the relationship between fruit and vegetable category and biomarkers but the association with body weight was no longer significant.

\section{Biomarker levels in smokers}

Plasma vitamin $\mathrm{C}$ and carotenoid concentrations have been reported to be lower in male Scottish smokers compared with non-smokers ${ }^{(29)}$. In the present study of women, although smokers had lower fruit and vegetable intakes this did not account completely for the differences in biomarkers between smokers and non-smokers. As smoking increases the catabolism of vitamin $C$, higher intakes of vitamin $C$ are required to maintain similar levels to those seen in non-smokers, which may explain the differences. The same may apply to the carotenoids. For $\beta$-cryptoxanthin there was a two-fold difference between smokers and non-smokers and most of the other carotenoids were lower in smokers, although not statistically significant. Lycopene, retinol and the vitamin $\mathrm{E}$ homologues, $\alpha$-tocopherol and $\gamma$-tocopherol, were almost identical. Urinary vitamin $\mathrm{K}$ metabolites were higher in the smokers. It is possible that the higher concentrations of vitamin $\mathrm{K}$ reflect a diet that is higher in fat in smokers. In a study of Scottish men, serum vitamin $\mathrm{K}$ was not found to be significantly different between smokers and non-smokers ${ }^{(30)}$. The differences in urinary metabolites seen in the present study may reflect altered vitamin $\mathrm{K}$ metabolism in smokers but a larger study is required to confirm the observation. Other studies have reported higher vitamin $\mathrm{E}$ levels in smokers compared with non-smokers ${ }^{(23,31)}$. Yet dietary intakes of vitamin $\mathrm{E}$ (and vitamin $\mathrm{C}$, total fibre, $\beta$-carotene and polyunsaturated:saturated fat ratio) were lowest in current smokers and highest in non-smokers ${ }^{(32)}$. Similarly smokers were found to have lower intakes of the antioxidant vitamins and fibre, but higher intakes of dietary cholesterol and alcohol than non-smokers ${ }^{(33)}$. There are suggestions that cholesterol metabolism may be altered in smokers ${ }^{(34)}$. The differences that we observed in plasma vitamin $\mathrm{C}$ concentrations between smokers and non-smokers were almost identical to results of a study where a third were smokers compared with $15 \%$ in the present study ${ }^{(23)}$.

\section{Strengths and limitations}

A limitation of the present study is that a pragmatic approach to the fruit and vegetable intervention was used whereby the number of portions per $d$ was specified but not the actual type of fruit and vegetables to be eaten; and overall diet was not controlled. For the sub-studies we did not have baseline measurements for carotenoids and only a limited number of $24 \mathrm{~h}$ urine measurements for the vitamin $\mathrm{K}$ metabolites. Its findings are restricted to healthy postmenopausal women. A major strength is the study duration of 2 years with freeliving participants being seen every 3 months and a range of biomarkers were tested.

\section{Conclusion}

Plasma homocysteine was not found to be a suitable marker of fruit and vegetable intake. Plasma vitamin $\mathrm{C}$ and whole-blood folate were associated with intakes of fruit, vegetables and total fruit and vegetables in our study population for the non-fruit and vegetable intervention group. Neither marker was suitable for assessing changes in fruit and vegetable intake, during the intervention, nor for assessing differences in intake between the fruit and vegetable and placebo groups. In contrast, although our data are limited, $\beta$-carotene and $\beta$-cryptoxanthin appear to be superior for assessing differences between the treatment groups. For the urinary vitamin $\mathrm{K}$ metabolites, these data are the first to be published in a UK population but further work is required to assess their usefulness as markers of fruit and vegetable intake.

In summary, the use of different biomarkers may be useful for monitoring fruit and vegetable intakes in populations. For monitoring enforced change in diet, however, their use may be restricted to a narrow range of fruit and vegetable intake, which will depend on the specific biomarker used, the type of fruit and vegetable being studied and the population under investigation.

\section{Acknowledgements}

The present study was funded by the Food Standards Agency (N05043). G. G. D. and S. J. D. acknowledge support from the Scottish Government Rural and Environment Research and Analysis Directorate (RERAD). Any views expressed are the authors' own. We are grateful to Alan Wise for his advice in analysing diets using Windiets, to Susan Lanham New for assistance in designing the dietary checklist, to Philip Morrice for technical support and to Dominic Harrington for analysis of the vitamin $\mathrm{K}$ metabolites. Thank you to all the women who took part and without whose commitment the present study would not have been possible.

H. M. M. was principal investigator, responsible for the study design, running the study and writing the manuscript. D. M. R. is director of the Aberdeen Prospective Osteoporosis Screening Study from where the volunteers were recruited and contributed to the study design; R. S. was the research nurse in charge of the study volunteers, contributing to advice on portion sizes and actively involved in qualitative research; A. C. H. processed, analysed and assisted with the interpretation of the food diaries, and entered data including dietary checklists; L. A. was the study statistician; G. G. D. analysed and interpreted the plasma vitamin $\mathrm{C}$, vitamin $\mathrm{E}$ and carotenoid results; S. J. D. analysed the samples for whole-blood folate and plasma homocysteine and interpreted the results; M. J. S. analysed and interpreted the vitamin K metabolite results. All authors critically appraised the manuscript.

None of the authors had any conflicts of interest.

\section{References}

1. He FJ, Nowson CA \& MacGregor GA (2006) Fruit and vegetable consumption and stroke: meta-analysis of cohort studies. Lancet 367, 320-326.

2. Bazzano LA, He J, Ogden LG, et al. (2002) Fruit and vegetable intake and risk of cardiovascular disease in US adults: the first National Health and Nutrition Examination Survey Epidemiologic Follow-up Study. Am J Clin Nutr 76, 93-99. 
3. Vainio H \& Weiderpass E (2006) Fruit and vegetables in cancer prevention. Nutr Cancer 54, 111-142.

4. World Cancer Research Fund (2007) Food, Nutrition, Physical Activity, and the Prevention of Cancer: a Global Perspective: The Second Expert Report. London: WCRF UK.

5. Guenther PM, Dodd KW, Reedy J, et al. (2006) Most Americans eat much less than recommended amounts of fruits and vegetables. J Am Diet Assoc 106, 1371-1379.

6. Henderson L, Gregory J \& Swan G (2003) National Diet and Nutrition Survey: adults aged 19 to 64 years, vol. 1, types and quantities of foods consumed. London: The Stationery Office.

7. Cox DN, Anderson AS, Reynolds J, et al. (1998) Take Five, a nutrition education intervention to increase fruit and vegetable intakes: impact on consumer choice and nutrient intakes. $\mathrm{Br} J$ Nutr 80, 123-131.

8. John JH, Ziebland S, Yudkin P, et al. (2002) Effects of fruit and vegetable consumption on plasma antioxidant concentrations and blood pressure: a randomised controlled trial. Lancet 359, 1969-1974.

9. Steptoe A, Perkins-Porras L, Rink E, et al. (2004) Psychological and social predictors of changes in fruit and vegetable consumption over 12 months following behavioral and nutrition education counseling. Health Psychol 23, 574-581.

10. Peterson KE, Hebert JR, Hurley TG, et al. (2008) Accuracy and precision of two short screeners to assess change in fruit and vegetable consumption among diverse populations participating in health promotion intervention trials. $J$ Nutr 138, 218S-225S.

11. Welch AA, Mulligan A, Bingham SA, et al. (2008) Urine $\mathrm{pH}$ is an indicator of dietary acid-base load, fruit and vegetables and meat intakes: results from the European Prospective Investigation into Cancer and Nutrition (EPIC)-Norfolk population study. Br J Nutr 99, 1335-1343.

12. Greene GW, Resnicow K, Thompson FE, et al. (2008) Correspondence of the NCI Fruit and Vegetable Screener to repeat $24 \mathrm{~h}$ recalls and serum carotenoids in behavioral intervention trials. J Nutr 138, 200S-204S.

13. Steptoe A, Perkins-Porras L, Hilton S, et al. (2004) Quality of life and self-rated health in relation to changes in fruit and vegetable intake and in plasma vitamins $C$ and $E$ in a randomised trial of behavioural and nutritional education counselling. Br J Nutr 92, 177-184.

14. Macdonald HM, Black AJ, Aucott L, et al. (2008) Effect of potassium citrate supplementation or increased fruit and vegetable intake on bone metabolism in healthy postmenopausal women: a randomized controlled trial. Am J Clin Nutr 88, $465-474$

15. Nelson M, Atkinson M \& Meyer J (1997) A Photographic Atlas of Food Portion Sizes. London: Ministry of Agriculture, Fisheries and Food.

16. Day N, McKeown N, Wong M, et al. (2001) Epidemiological assessment of diet: a comparison of a 7-day diary with a food frequency questionnaire using urinary markers of nitrogen, potassium and sodium. Int J Epidemiol 30, 309-317.

17. Macdonald HM, New SA \& Reid DM (2005) Longitudinal changes in dietary intake in Scottish women around the menopause: changes in dietary pattern result in minor changes in nutrient intake. Public Health Nutr 8, 409-416.
18. Food Standards Agency (2002) Food Portion Sizes. London: The Stationery Office.

19. Tunstall-Pedoe H, Smith WCS, Crombie IK, et al. (1989) Coronary risk factor and lifestyle variation across Scotland: results from the Scottish Heart Health Study. Scot Med J 34, 556-560.

20. Duthie GG (1999) Determination of activity of antioxidants in human subjects. Proc Nutr Soc 58, 1015-1024.

21. Harrington DJ, Soper R, Edwards C, et al. (2005) Determination of the urinary aglycone metabolites of vitamin K by HPLC with redox-mode electrochemical detection. J Lipid Res 46, $1053-1060$.

22. Levine M, Conry-Cantilena C, Wang Y, et al. (1996) Vitamin C pharmacokinetics in healthy volunteers: evidence for a recommended dietary allowance. Proc Natl Acad Sci U S A 93, 3704-3709.

23. Cappuccio FP, Rink E, Perkins-Porras L, et al. (2003) Estimation of fruit and vegetable intake using a two-item dietary questionnaire: a potential tool for primary health care workers. Nutr Metab Cardiovasc Dis 13, 12-19.

24. Harding AH, Wareham NJ, Bingham SA, et al. (2008) Plasma vitamin $\mathrm{C}$ level, fruit and vegetable consumption, and the risk of new-onset type 2 diabetes mellitus: the European Prospective Investigation of Cancer-Norfolk prospective study. Arch Intern Med 168, 1493-1499.

25. Macdonald HM, McGuigan FE, Fraser WD, et al. (2004) Methylenetetrahydrofolate reductase polymorphism interacts with riboflavin intake to influence bone mineral density. Bone 35, 957-964.

26. Bogers RP, Dagnelie PC, Bast A, et al. (2007) Effect of increased vegetable and fruit consumption on plasma folate and homocysteine concentrations. Nutrition 23, 97-102.

27. Brouwer IA, van Dusseldorp M, West CE, et al. (1999) Dietary folate from vegetables and citrus fruit decreases plasma homocysteine concentrations in humans in a dietary controlled trial. J Nutr 129, 1135-1139.

28. Tucker KL, Chen H, Vogel S, et al. (1999) Carotenoid intakes, assessed by dietary questionnaire, are associated with plasma carotenoid concentrations in an elderly population. $J$ Nutr 129, 438-445.

29. Ross MA, Crosley LK, Brown KM, et al. (1995) Plasma concentrations of carotenoids and antioxidant vitamins in Scottish males: influences of smoking. Eur J Clin Nutr 49, 861-865.

30. Fenton S, Bolton-Smith C, Harrington D, et al. (1994) Dietary vitamin K (phylloquinone) intake in Scottish men. Proc Nutr Soc 53, 98A

31. Armstrong NC, Paganga G, Brunner E, et al. (1997) Reference values for $\alpha$-tocopherol and $\beta$-carotene in the Whitehall II Study. Free Radic Res 27, 207-219.

32. Cade JE \& Margetts BM (1991) Relationship between diet and smoking - is the diet of smokers different? J Epidemiol Community Health 45, 270-272.

33. Woodward M, Bolton-Smith C \& Tunstall-Pedoe H (1994) Deficient health knowledge, diet, and other lifestyles in smokers: is a multifactorial approach required? Prev Med 23, 354-361.

34. de Parscau L \& Fielding CJ (1986) Abnormal plasma cholesterol metabolism in cigarette smokers. Metabolism $\mathbf{3 5}$, $1070-1073$. 